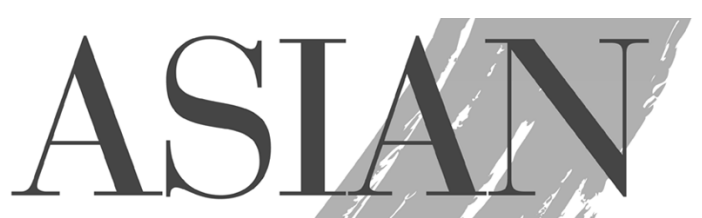

CARDIOVASCULAR \& THORACIC

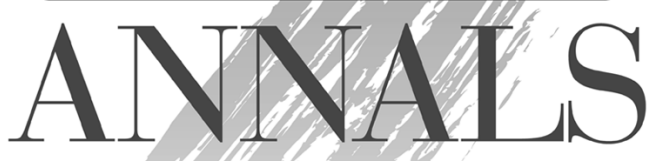

\title{
Pulmonary Artery Leiomyosarcoma Successfully Treated by Right Pneumonectomy
}

Franco Stella, Fabio Davoli, Jury Brandolini, Giampiero Dolci, Francesco Sellitri and Alessandro Bini

Asian Cardiovasc Thorac Ann 2009; 17:513-515

DOI: $10.1177 / 0218492309348631$

This information is current as of December 27, 2011

The online version of this article, along with updated information and services, is located on the World Wide Web at:

http://asianannals.ctsnetjournals.org/cgi/content/full/17/5/513 


\title{
Pulmonary Artery Leiomyosarcoma Successfully Treated by Right Pneumonectomy
}

\author{
Franco Stella, MD, Fabio Davoli, MD, Jury Brandolini, MD, Giampiero Dolci, MD, \\ Francesco Sellitri, MD, Alessandro Bini, MD
}

Department of Thoracic Surgery

S. Orsola-Malpighi Hospital, University of Bologna

Bologna, Italy

\begin{abstract}
A 79-year-old woman had a primary tumor of the pulmonary artery, which was initially diagnosed as chronic pulmonary thromboembolism. Multislice angio-computed tomography showed a solid mass in the right pulmonary artery. Radical resection of the tumor was achieved by right pneumonectomy via a transsternal transpericardial approach. The patient was alive and free of disease 36 months after surgery.
\end{abstract}

(Asian Cardiovasc Thorac Ann 2009;17:513-5)

KEYWORDS: Leiomyosarcoma, Pneumonectomy, Pulmonary Artery, Sarcoma

\section{INTRODUCTION}

Primary sarcomas of the great vessels are extremely rare. They usually present in patients aged $45-50$ years, and dyspnea is the most common symptom. The initial diagnosis is often pulmonary embolism. ${ }^{1}$ Primary sarcoma of the pulmonary artery generally involves both the pulmonary trunk and one or both pulmonary arteries. It spreads throughout the lumen with intraluminal polypoid growths. Distal luminal extension and pulmonary parenchymal masses are common. Metastatic sites include the lungs, kidneys, brain, lymph nodes, and skin. ${ }^{2}$ The only effective therapy for primary sarcoma of the pulmonary artery is surgical resection. The prognosis is poor: without treatment, patients die within a few months; and the median survival after surgical resection does not exceed 24 months, despite isolated cases of long survival up to 62 months after resection.,

\section{CASE RePORT}

A 79-year-old woman with a primary tumor of the pulmonary artery, suspected to be primary sarcoma of the pulmonary artery, was admitted to our department with a 2-year history of exertional dyspnea, initially diagnosed as chronic pulmonary thromboembolism.
Optimal anticoagulant treatment did not resolve her symptoms, and she had periods of good health interspersed with recurrent episodes of worsening fatigue and shortness of breath, which were treated by oxygen therapy. Multislice angio-computed tomography (CT) with 3-dimensional reconstruction 2 years after the $1^{\text {st }}$ episode of dyspnea showed a solid mass in the right pulmonary artery, $3 \mathrm{~cm}$ from its origin, reported as an intraarterial heteroplasm with intraluminal diffusion to the principal branches (Figure 1). A total body CT scan did not show metastatic spread to other areas. Subsequent pulmonary perfusion scintigraphy demonstrated a severe right-sided perfusion defect. Considering the clinical presentation and radiological findings, radical resection of the tumor was attempted via a median sternotomy. The pericardium was opened and the right branch of the pulmonary artery was explored: at the origin of its first mediastinal branch, it appeared to be entirely occupied by a yellowish-white endoluminal mass. Exposure of the right pleural space allowed good vision of the pulmonary parenchyma which appeared to be invaded by other neoformations in several places. A right pneumonectomy was performed. Because pulmonary artery clamping did not induce

Fabio Davoli, MD Tel: +39 $3491597046 \quad$ Fax: +39051307022Ｅmail: fab_78_161@hotmail.com

Department of Thoracic Surgery, University of Bologna “S. Orsola-Malpighi'” Hospital, Via Massarenti, 9, 40138

Bologna (BO), Italy.

doi: 10.1177/0218492309348631

(C) SAGE Publications 2009 Los Angeles, London, New Delhi and Singapore

2009, VOL. 17, NO. $5 \quad 513 \quad$ ASIAN CARDIOVASCULAR \& THORACIC ANNALS

Downloaded from asianannals.ctsnetjournals.org by on December 27, 2011 

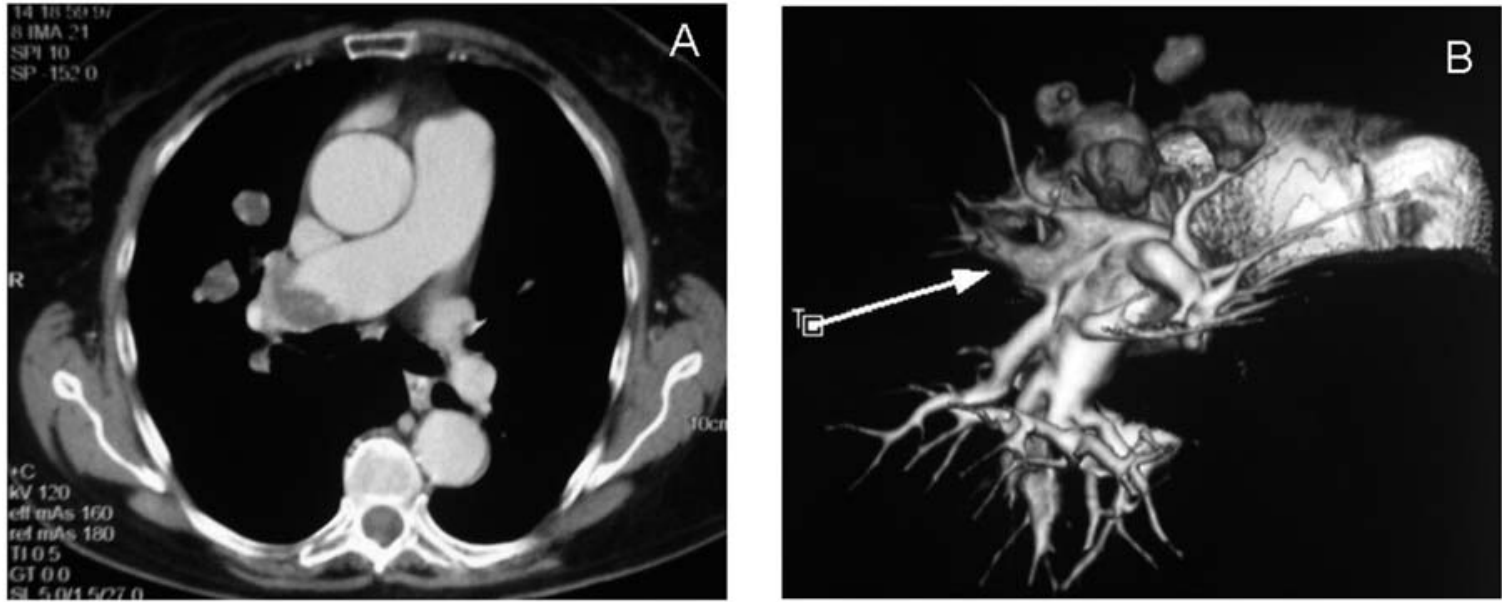

Figure 1. (A) Contrast-enhanced computed tomography revealing a mass in the right pulmonary artery with an intraluminal filling defect and 3 nodular masses appearing as opacities in the right pulmonary parenchyma. (B) Multislice angio-computed tomography with 3-dimensional reconstruction.
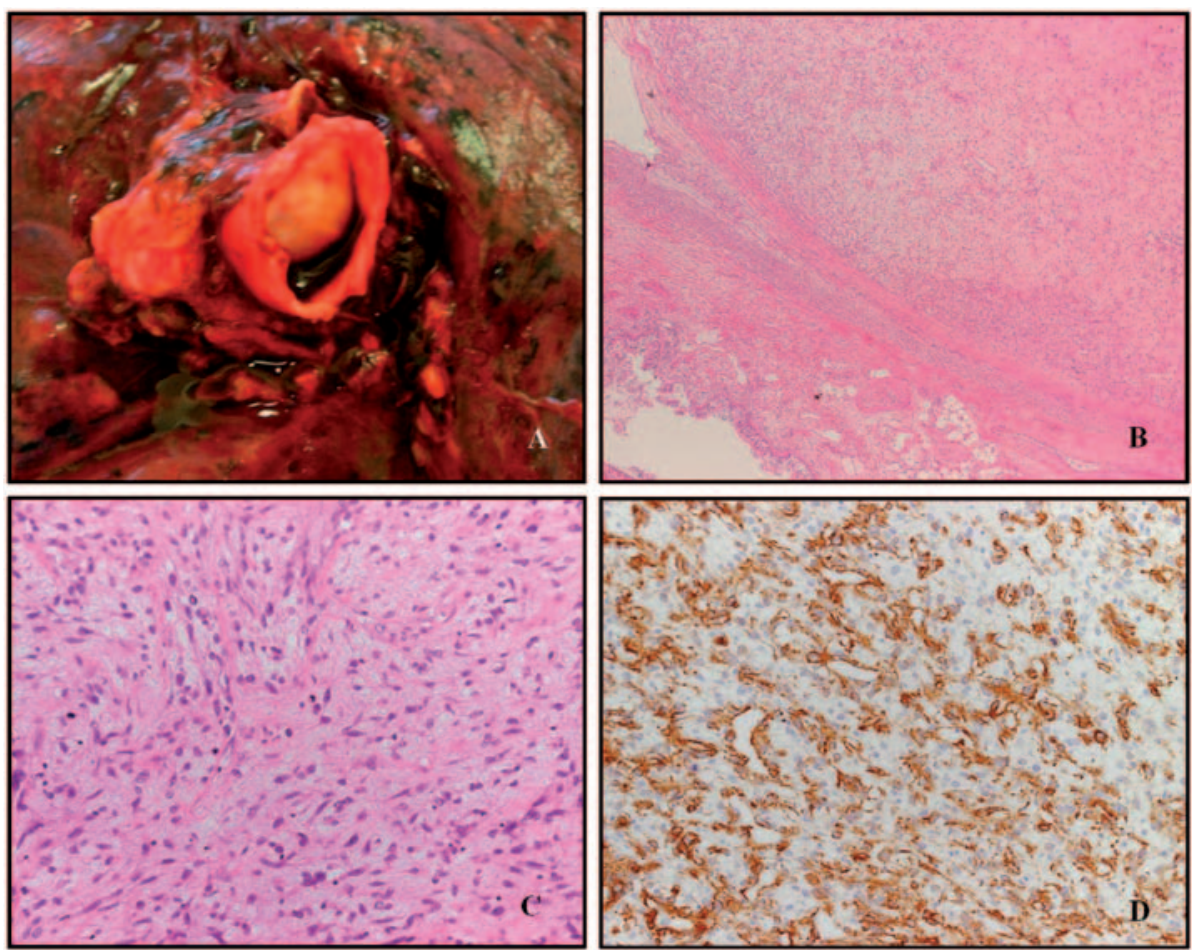

Figure 2. (A) Macroscopic specimen: the tumor appears as a yellowish endoluminal mass completely filling the arterial lumen. (B) Pulmonary artery leiomyosarcoma: intraluminal protrusion of the tumor (hematoxylin and eosin stain, original magnification $\times 4$ ). (C) The neoplasm is characterized by pleomorphic spindle cells with a storiform growth pattern (hematoxylin and eosin stain, original magnification $\times 20$ ). (D) Leiomyosarcoma of the pulmonary artery with cells positive for smooth muscle actin (original magnification $\times 20$ ).

marked hemodynamic or oxygen saturation changes, closed proximal resection of the right pulmonary artery branch was carried out using a continuous suture. After completing the pneumonectomy, the pericardial defect was covered with a Gore-Tex patch. The patient was discharged on postoperative day 30 in good clinical condition. She was alive and free of disease 36 months after surgery.
Grossly, the tumor appeared to be a nodular mass arising inside the lumen and adhering to the vessel wall (Figure 2A). On opening the pulmonary artery, the hard yellowish-white tissue of the mass was found to extend along the arterial lumen and infiltrate the vessel wall and pulmonary parenchyma. Histologically, the neoplasm was composed of spindle cells with a storiform growth pattern and pleomorphic nuclei, with a high 
mitotic activity (mitotic count $>5-10$ in 10 high-power fields). Necrosis was present in $<50 \%$ of the tumor (Figures 2B and 2C). Immunohistochemical examination showed positive smooth-muscle actin differentiation (Figure 2D). Immunomorphology confirmed the diagnosis of leiomyosarcoma G4 of the pulmonary artery, extending to the pulmonary parenchyma by endoarterial spreading.

\section{Discussion}

Primary sarcomas of the pulmonary artery represent a diagnostic dilemma: the presenting symptoms are usually nonspecific, and the most frequent misdiagnosis until biopsy or surgery is pulmonary embolism. In our patient, we believe it would have been impossible to achieve the correct diagnosis without multislice angioCT with 3-dimensional reconstruction. Several reports have suggested that CT, magnetic resonance imaging, and positron-emission tomography may be the most useful modalities for differentiation between a tumor and thrombotic material. ${ }^{4-6}$

We choose the transsternal approach because of the extent of the tumor near the pulmonary trunk. We believe it affords more control of the heart and great vessels, allowing institution of cardiopulmonary bypass if necessary. Moreover, a median sternotomy is less detrimental to respiratory function than the standard posterolateral thoracotomy. Surgical treatment is strongly indicated in these patients: median survival without surgery is limited to 1.5 months. ${ }^{1}$ Complete resection can result in acceptable survival. In the Massachusetts General Hospital series, the actuarial 3- and 5-year survival rates were $69 \% .^{7}$ The roles of adjuvant or neoadjuvant treatments need to be defined; both might increase the length of survival, but currently available data are insufficient to confirm this. ${ }^{8}$

\section{REFERENCES}

1. Krüger I, Borowski A, Horst M, de Vivie ER, Theissen P, GrossFengels W. Symptoms, diagnosis and therapy of primary sarcomas of the pulmonary artery. Thorac Cardiovasc Surg 1990;38:91-5.

2. Burke AP, Virmani R. Sarcomas of the great vessels. A clinicopathologic study. Cancer 1993;71:1761-73.

3. Mayer E, Kriegsmann J, Gaumann A, Kauczor HU, Dahm M, Hake U, et al. Surgical Treatment of pulmonary artery sarcoma. J Thorac Cardiovasc Surg 2001;121:77-82.

4. Kauczor HU, Schwickert HC, Mayer E, Kersjes W, Moll R, Schweden F. Pulmonary artery sarcoma mimicking chronic thromboembolic disease: computed tomography and magnetic resonance imaging findings. Cardiovasc Intervent Radiol 1994;17:185-9.

5. Fasse A, Kauczor HU, Mayer E, Kreitner KF, Heussel CP, Thelen M. Sarcoma of the pulmonary artery pre- and postoperative radiologic findings in initial tumor manifestation and recurrence. Rofo 1999;170:112-8.

6. Kim JH, Gutierrez FR, Lee EY, Semenkovich J, Bae KT, Ylagan LR. Primary leiomyosarcoma of the pulmonary artery: a diagnostic dilemma. J Clin Imaging 2003;27:206-11.

7. Bacha EA, Wright CD, Grillo HC, Wain JC, Moncure A, Keel SB, et al. Surgical treatment of primary pulmonary sarcomas. Eur J Cardiothorac Surg 1999;15:456-60.

8. Zerkowski HR, Hofmann HS, Gybels I, Knolle J. Primary sarcomas of pulmonary artery and valve: multimodality treatment by chemotherapy and homograft replacement. J Thorac Cardiovasc Surg 1996;112:1122-4. 


\section{Pulmonary Artery Leiomyosarcoma Successfully Treated by Right Pneumonectomy}

Franco Stella, Fabio Davoli, Jury Brandolini, Giampiero Dolci, Francesco Sellitri and Alessandro Bini

Asian Cardiovasc Thorac Ann 2009;17:513-515

DOI: $10.1177 / 0218492309348631$

This information is current as of December 27, 2011

\section{Updated Information \& Services \\ References}

Permissions \& Licensing

Reprints including high-resolution figures, can be found at: http://asianannals.ctsnetjournals.org/cgi/content/full/17/5/513

This article cites 8 articles, 2 of which you can access for free at: http://asianannals.ctsnetjournals.org/cgi/content/full/17/5/513\#BIB $\mathrm{L}$

Requests to reproduce this article in parts (figures, tables) or in its entirety should be submitted via email to: info@ asiapex.com

For ordering reprints, please email: info@ asiapex.com

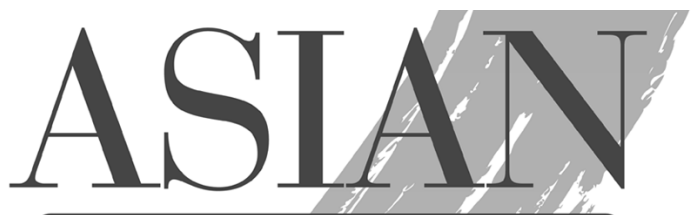

CARDIOVASCULAR \& THORACIC

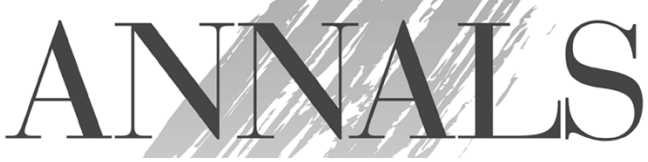

